PESQUISAS EM BIOÉTICA NO BRASIL DE HOJE. Garrafa V, Cordón J, organizadores. São Paulo: Editora Gaia; 2006. 256 pp.

ISBN: 85-7555-079-9

A Bioética não é mais uma disciplina em busca de sua afirmação em nosso país. Embora seja razoável descrevê-la como tardia, como tantas vezes Volnei Garrafa o fez, também é afirmar que seu desenvolvimento está diretamente relacionado com a consolidação da democracia formal que pode ser reconhecida na promulgação da Constituição democrática de 1988. Alguns de seus marcos também podem ser identificados na aprovação das Resoluções 1/1988 e 196/1996 do Conselho Nacional de Saúde - ambas relacionadas com a ética em pesquisas envolvendo seres humanos, com a criação da Revista Bioética pelo Conselho Federal de Medicina em 1993, a criação da Sociedade Brasileira de Bioética e com a realização do $1^{\circ}$. Congresso Brasileiro de Bioética. Outro marco igualmente relevante no desenvolvimento e consolidação do campo disciplinar da Bioética foi, sem sombra de dúvida, a criação do primeiro curso de especialização em Bioética, por Volnei Garrafa, na Universidade de Brasília. Este livro está relacionado com esse último marco. Não exatamente com a primeira edição do referido curso, mas com sua sexta edição, realizada em 2004. O livro organizado por Garrafa \& Cordón traz os resultados de 12 projetos de pesquisa desenvolvidos por 33 alunos do curso, que coincidiu com a criação da Cátedra da Unesco de Bioética na Universidade de Brasília (UnB).

O livro está organizado de acordo com a própria lógica do curso e das linhas de pesquisa em Bioética na UnB: fundamentos epistemológicos, situações emergentes em Bioética e situações persistentes em Bioética, segundo os coordenadores da publicação. De fato, inicia-se com uma discussão sobre aquelas que são identificadas pelos autores como "escolas emergentes da bioética brasileira: bioética da reflexão autônoma, bioética da intervenção, bioética da proteção, bioética da teologia da libertação, bioética crítica de inspiração feminista e bioética feminista e anti-racista" (p. 20). Embora nem todas as "escolas" possam ser de fato assim denominadas, o capítulo oferece ao leitor um breve panorama da produção em Bioética no Brasil. Além desse, apenas os capítulos dois da primeira parte (uma análise bioética da legislação brasileira aplicável ao uso de animais não-humanos em experimentos científicos); três da segunda, sobre o uso autólogo e alogênico do cordão umbilical e; seis da terceira parte, sobre o tráfico da fauna silvestre brasileira, não realizam um trabalho de campo de pesquisa com métodos das ciências sociais. Essa característica também está presente em boa parte da produção acadêmica brasileira em Bioética, o que precisaria ser quantificado para uma correta avaliação do fenômeno em nosso país. O fenômeno, entretanto, não é apenas brasileiro, sendo objeto de análise e reflexão em diversas publicações nos últimos anos, como já reconhecia Sugarman \& Faden em 1995 1. O avanço nessa discussão chega ao ponto de se propor uma Bioética Baseada em Evidências 2,3 ou discutir qual a contribuição que as ciências sociais podem oferecer para a reflexão bioética 4,5 . Embora Garrafa \& Cordón não nos ofereçam esse tipo de reflexão teórica, o conjunto de trabalhos da coletânea e a diversidade de métodos e referenciais teóricos oferecidos garantem ao leitor acesso a uma boa amostra das pesquisas que são realizadas no âmbito da Cátedra de Bioética da Unesco na UnB, com sua especial atenção e foco nos problemas morais relacionados com o bem-estar das coletividades. Abordando desde o emergente problema da lipodistrofia em pacientes com AIDS, do longo caminho percorrido por mulheres que necessitam realizar tratamentos de reprodução assistida na rede pública de saúde, até as complexas questões relacionadas com o debate sobre doação de órgãos e o diagnóstico de morte encefálica.

A última parte do livro é dedicada à análise de algumas situações persistentes em nosso universo sanitário, com seis trabalhos que contemplam grande diversidade temática e conceitual: surtos de hantavirose no Distrito Federal, o trabalho do agente comunitário de saúde, os (maus) hábitos alimentares baseados na Fast Food, as doenças de transmissão hídrica e os problemas de acesso a transporte público e gratuito a portadores de deficiência mental.

Como uma coletânea, falta uma certa unidade conceitual e metodológica ao livro, mas tal fato não se constitui em problema para o leitor, que poderá sim buscar os temas e referenciais que lhe sejam mais caros, estabelecendo a sua própria ordem de leitura aos capítulos. A diversidade conceitual e metodológica presente no livro garante ao leitor um constante recomeçar a cada capítulo, o que também não prejudica a qualidade da obra ou o interesse que ela é capaz de despertar nos estudiosos da Bioética.

\section{Sergio Rego}

Escola Nacional de Saúde Pública Sergio Arouca, Fundação Oswaldo Cruz, Rio de Janeiro, Brasil. rego@ensp.fiocruz.br

1. Goldenberg MJ. Evidence based ethics? On evidence-based practice and the "empirical turn" from normative bioethics. BMC Med Ethics 2005; 6:E11.

2. Haimes E. What can the social sciences contribute to the study of ethics? Theoretical, empirical and substantive considerations. Bioethics 2002; 16:89-113

3. Halpern SD. Towards evidence based bioethics. BMJ 2005; 331:901-3.

4. Hedgecoe A. Critical bioethics: beyond the social science critique of applied ethics. Bioethics 2004; 18:120-43.

5. Sugarman J, Faden RR. The scope of empirical research in bioethics. http://www.cochrane.org/ colloquia/abstracts/oslo/Oslo11.htm (acessado em 26/Mai/2008). 